\title{
Modelling the impacts of new diagnostic tools for tuberculosis in developing countries to enhance policy decisions
}

\author{
Ivor Langley • Basra Doulla $\cdot$ Hsien-Ho Lin • \\ Kerry Millington $\cdot$ Bertie Squire
}

Received: 20 October 2011 / Accepted: 1 May 2012 / Published online: 7 June 2012

(C) The Author(s) 2012. This article is published with open access at Springerlink.com

\begin{abstract}
The introduction and scale-up of new tools for the diagnosis of Tuberculosis (TB) in developing countries has the potential to make a huge difference to the lives of millions of people living in poverty. To achieve this, policy makers need the information to make the right decisions about which new tools to implement and where in the diagnostic algorithm to apply them most effectively. These decisions are difficult as the new tools are often expensive to implement and use, and the health system and patient impacts uncertain, particularly in developing countries where there is a high burden of TB. The authors demonstrate that a discrete event simulation model could play a significant part in improving and informing these decisions. The feasibility of linking the discrete event simulation to a dynamic epidemiology model is also explored in order to take account of longer term impacts on the incidence of TB. Results from two diagnostic districts in Tanzania are
\end{abstract}

I. Langley $(\bowtie) \cdot$ K. Millington $\cdot$ B. Squire

Clinical Group,

Liverpool School of Tropical Medicine,

Liverpool, UK

e-mail: ivorlang@liv.ac.uk

K. Millington

e-mail: Kerry.millington@liv.ac.uk

B. Squire

e-mail: sbsquire@liv.ac.uk

B. Doulla

National Tuberculosis and Leprosy Programme,

Ministry of Health and Social Welfare,

Dar es Salaam, Tanzania

e-mail: bedoulla@yahoo.com

H.-H. Lin

Institute of Epidemiology and Preventive Medicine,

National Taiwan University,

Taipei, Taiwan

e-mail: hsienho@gmail.com used to illustrate how the approach could be used to improve decisions.

Keywords Developing Countries · Simulation · Transmission modelling $\cdot$ Cost effectiveness $\cdot$ Tuberculosis

\section{Introduction}

According to the World Health Organization (WHO) there were 8.8 million new cases and 1.4 million deaths resulting from Tuberculosis (TB) in 2010. TB is the archetypal disease of poverty and has highest incidence rates in the countries of sub-Saharan Africa, where pulmonary TB accounts for $81 \%$ of all notified cases. It is estimated over $10 \%$ of TB cases are Human Immunodeficiency Virus (HIV) positive, with $82 \%$ of these cases living in Africa [1]. Highly cost-effective antibiotic treatment for TB is readily available, however the failure to diagnose cases rapidly means TB remains a major threat to public health [2]. TB is an infectious airborne disease and the WHO estimate that every individual left untreated infects a further 10 to 15 people every year [1]. Therefore, the delays in diagnosis not only result in poor treatment outcomes at the individual level, but also longer infectious periods resulting in sustained transmission at the community level.

The standard approach for the diagnosis of pulmonary TB relies on microscopic evaluation of sputum samples collected from individuals suspected of having TB. The process that a typical individual showing symptoms of TB would need to follow in order to access diagnosis and treatment is illustrated in a simplified flow diagram in Fig. 1. Published research shows that in the developing world this process presents a number of barriers to infected individuals that limit its effectiveness [3-5]. A major barrier 
is the time spent (and therefore high cost relative to income incurred) by the poor in accessing diagnosis even when the consultation process and treatment itself are provided free of charge. This is due to the high number of separate visits to the diagnostic centre that are required (at least three) and the distances that sick individuals need to travel usually on foot to receive a TB diagnosis [3]. These factors lead to many individuals either not starting the diagnostic process, or starting but not completing diagnosis (diagnostic default) or treatment (treatment default).

Efforts by organisations such as the Stop-TB partnership [2] and the Foundation for Innovative New Diagnostics (FIND) to stimulate innovation in the processes and technology of TB diagnosis have resulted in the development of several innovative diagnostic tools and improved algorithms [6-10]. Some of these optimise existing technologies e.g. using updated microscopes (light-emitting diode (LED) fluorescence microscopes [6]), whilst others involve introducing new, innovative and much more expensive technologies such as automated nucleic acid amplification tests (aNAAT) [7, 10]. These tests identify targeted nucleic acid sequences in the TB genome that can provide results from sputum samples in less than two hours. These new technologies can replace microscopy as the primary tool for initial TB diagnosis, but involve retraining staff, significant investment in equipment and expensive consumables for each individual test.

WHO requires evidence to endorse any new diagnostic tool or combinations of tools in order to formulate guidelines and recommendations [11]. The evidence required by this process is generally presented in the form of systematic reviews of accuracy or efficacy based on test or demonstration studies. These summarise the quality of evidence about whether innovations can work based on observed sensitivity and specificity. Evidence about whether they will actually work or their likely impacts in different contexts is usually lacking [12]. For example, different diagnostic strategies could be more or less cost effective in settings with different levels of HIV, drug resistance, or access to other health facilities. We suggest that a more complete comparison of the impacts of different diagnostic strategies is required by policy makers within resourced constrained developing countries if they are to successfully implement cost effective solutions for their specific context [13]. Controlled trials to compare all the available options in order to understand the health system, patient, and transmission impacts of different TB diagnostic tools are in reality impractical due to the wide array of options and contexts. Therefore, a modelling approach is proposed that uses the data from current practice in the context being considered, alongside the data from demonstration trials of the new technologies from a different context, to project the future impacts of changes in diagnostic tool or algorithm. Once the model is developed it can then be updated as new information from trials and current practice becomes available. It can also be adapted through data feeds and other inputs to model other contexts.

Here we use an original application of discrete event simulation (DES) to model the health system for TB diagnosis and treatment in developing countries. An application of the model using data from Tanzania demonstrates how the approach can enhance understanding and quantification of the impacts in
Fig. 1 TB diagnosis and treatment flow diagram

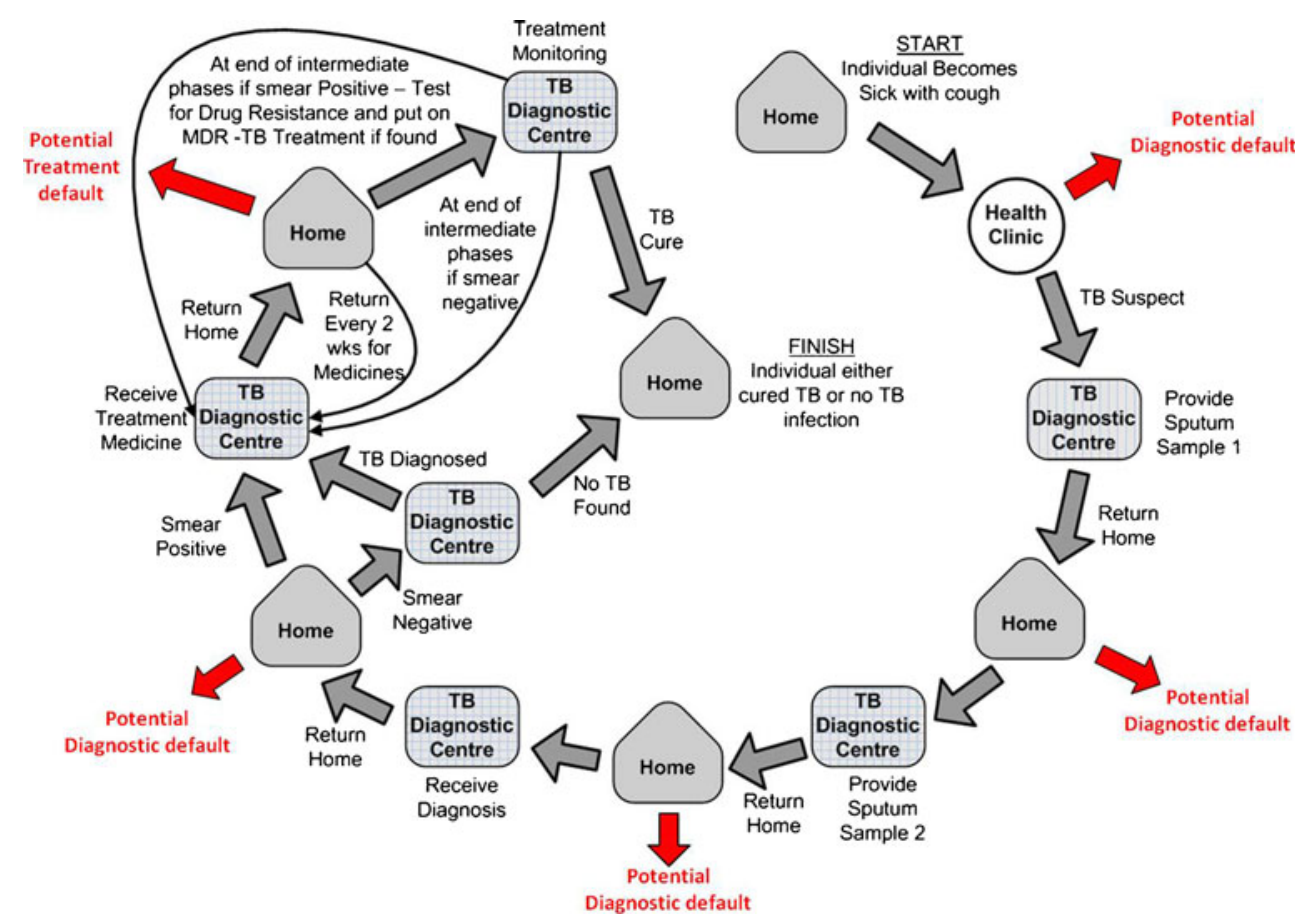


order to facilitate rational and improved decisions by policy makers. The approach uses, as an example, the potential full implementation of aNAAT (e.g. Xpert MTB/RIF [6]) in district TB laboratories in Tanzania to show that a flexible and informative model can be developed. Full implementation of aNAAT is compared to the current technology - Ziehl Neelsen (ZN) microscopy, optimised smear microscopy using LED fluorescence microscopes, and partial implementation of aNAAT for individuals who are HIV positive. The feasibility of improving future, longer term predictions by taking account of the impacts on TB incidence through a link to a disease transmission model is also explored.

\section{Method selection}

A review of the questions that policy makers need to address in order to decide which of the available diagnostic tools and algorithms for a specific context to implement was undertaken. The results of this review were matched to a framework proposed by Mann et al. [13] for creating a comprehensive evidence base for TB diagnostics. The framework, called the Impact Assessment Framework (IAF), is a systematic way of compiling, and checking for completeness, the questions that policy makers and researchers need to consider. Table 1 shows the IAF populated by the key questions that the modelling would need to address. In order to help answer all these questions the model would require both a detailed operational component, to understand patient and health system effects, as well as a disease transmission component to understand impacts on the community. This paper is primarily focused on the operational component. In order to understand whether a comprehensive modelling approach could be developed that covered projections of TB incidence as well, a link to a disease transmission model was also tested. The operational component and the link to the disease transmission component are discussed below.

\subsection{Operational component}

The operational component needed to model the movement of patients and sputum samples through the health system in order to understand the impacts of different diagnostic tools and algorithms on patients and the health system. Such an approach would highlight any bottlenecks in the diagnostic process and enable potential remedies to be investigated. The

Table 1 Impact assessment framework-questions that the modelling should seek to address

\begin{tabular}{|c|c|c|c|}
\hline \multirow[t]{2}{*}{ Assessment layer } & \multicolumn{3}{|l|}{ Stakeholder } \\
\hline & Patient & Ministry of health & Community \\
\hline $\begin{array}{l}\text { EFFICACY } \\
\text {-How well does it work? }\end{array}$ & $\begin{array}{l}\text { What is the increase in patients } \\
\text { diagnosed and cured? }\end{array}$ & $\begin{array}{l}\text { How many more TB treatments required? } \\
\text { Will it reduce wastage }-(\text { e.g. } \\
\text { reduce false positive results }) ?\end{array}$ & \\
\hline $\begin{array}{l}\text { EQUITY } \\
\text {-Who benefits? }\end{array}$ & $\begin{array}{l}\text { Do HIV+ patients benefit? } \\
\text { Will it benefit the poor? } \\
\text { Will MDR-TB patients benefit? }\end{array}$ & Staff impacts? & \\
\hline $\begin{array}{l}\text { HEALTH SYSTEM } \\
\text {-Operational Effects }\end{array}$ & $\begin{array}{l}\text { Will it reduce patient visits and } \\
\text { waiting time? } \\
\text { How much quicker will patients } \\
\text { be treated? }\end{array}$ & $\begin{array}{l}\text { Staffing numbers and utilisation? } \\
\text { How much will it affect running costs? } \\
\text { What is the effect on the number of } \\
\text { samples collected? } \\
\text { Will it overcome bottlenecks or just } \\
\text { move them on? } \\
\text { Where in the diagnostic algorithm should } \\
\text { the new test be placed? }\end{array}$ & \\
\hline $\begin{array}{l}\text { SCALE-UP } \\
\text {-Impacts of national roll-out }\end{array}$ & $\begin{array}{l}\text { How many patients will benefit } \\
\text { if rolled out? }\end{array}$ & $\begin{array}{l}\text { Where to start? } \\
\text { How much will it cost? } \\
\text { Is it cost effective? }\end{array}$ & $\begin{array}{l}\text { What will the impact be on TB } \\
\text { incidence and prevalence? }\end{array}$ \\
\hline $\begin{array}{l}\text { HORIZON SCANNING } \\
\text {-What else is coming along? }\end{array}$ & $\begin{array}{l}\text { Will it mean more patients seek } \\
\text { diagnosis? }\end{array}$ & $\begin{array}{l}\text { What if: new tests become available, } \\
\text { performance changes, targeted } \\
\text { differently, numbers increase/decrease? }\end{array}$ & $\begin{array}{l}\text { Will it contribute to achieving the } \\
2015 / 2050 \text { millennium development } \\
\text { goals for TB? }\end{array}$ \\
\hline
\end{tabular}


chosen modelling software would require an interactive model building capability which researchers could use without the need for programming skills. The model would need to be flexible to enable a number of different diagnostic scenarios and contexts to be represented without major redevelopment. Essential would be the ability to link to standard databases holding input and output data, and a visual representation of the modelled processes in order to improve engagement and assist in validation with experts in Tanzania. All these features made using a commercially available discrete event simulation (DES) package an attractive proposition.

DES is used extensively in the developed world to model processes within health systems, and other commercial and public sector situations [14-17]. However, there is considerably less published material on the use of DES in health studies in developing countries. A number of different DES simulation modelling tools could be used to model the health systems as proposed. For this study the Witness simulation package [18] was selected as it provided the features necessary and was available within the institution carrying out the research. The supplier licensing the software agreed that national TB programmes within developing countries could have access to the developed model for experimentation purposes at no cost.

\subsection{Linked operational and disease transmission components}

To understand the transmission impacts of different diagnostic tools and algorithms a dynamic epidemiological component would be required. This component would need to model at a different level (national or large regional area) to the detailed operational component (district) with key outputs being projections of incidence and prevalence of TB over many years. Dynamic epidemiological models of TB transmission using differential equations to solve are well established. They specify how a population is divided into mutually exclusive health states and how the flow between states depends on the current state of the system [19-23]. Incorporating a disease transmission component within multiple district level DES models would be possible, but would add complexity and be time consuming in terms of development. It was therefore decided to test a link to a disease transmission component based on a differential equation model of the type discussed by Murray and Solomon [20], but adapted to incorporate the health system dynamics for the diagnostic tool being employed.

The link between the operational and disease transmission components would be established by creating input and output cells within the databases used by each individual component that would be populated by data from the other component. Figure 2 illustrates this link. This structure would also allow each component to be developed independently by researchers in separate institutions and countries, with the links between them provided by Excel databases. The key parameter that the operational component would source from the disease transmission component would be TB incidence, and hence the number of people seeking TB diagnosis. The disease transmission component would source two parameters from the operational component. These would be the proportion of individuals seeking diagnosis that fail to complete this process (diagnostic default rate) and the time it takes for individuals from initially seeking diagnosis to completing diagnosis and starting TB treatment. These parameters are critical to disease transmission as they contribute to the time that individuals are infectious with $\mathrm{TB}$ and therefore the number of people that contract active TB. This study would show if such a link would be a practical approach or whether the health system and transmission elements of the model would need integrating into a single tool.

\section{Model building}

\subsection{Model structure}

A discrete event simulation of the health system using Witness was developed that encompassed the patient

Fig. 2 Linked operational and disease transmission components

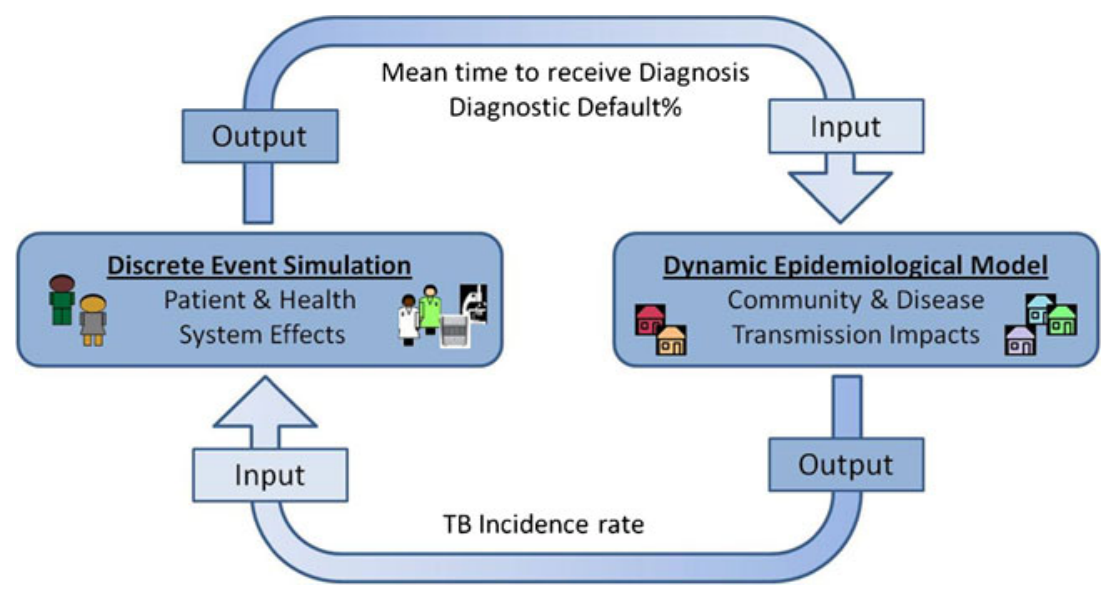


pathways and the processes that sputum samples followed as illustrated in Fig. 3. Theses processes followed the WHO's published guidelines [24, 25]. The patient pathway started at the point where individuals with TB symptoms arrived at the district TB diagnostic centre and continued through diagnosis, to the completion of TB treatment. The flow of sputum samples was modelled starting at sputum collection from the patient in the diagnostic centre then through each element of the laboratory services where testing takes place and potential bottlenecks can occur. When drug resistance was suspected, the transportation of samples to the central TB reference laboratory (CTRL) and the stages within drug sensitivity testing were modelled.

The key elements within the Witness DES model were entities (representing patients, sputum samples, and transport); activities (representing reception, sputum collection, clinical consultation, X-ray, sample preparation, sample testing, sample examination, treatment education, and drug sensitivity testing); queues (representing prior buffers to each activity, patient waiting areas, and the treatment stages); and resources (representing clinicians, nurses, diagnostic centre and CTRL laboratory staff).

\subsection{Input parameters}

The main input parameters, probability distributions, and data sources are shown in Table 2. The cost estimates are in US dollars and are based on estimates provided by the National TB and Leprosy Programme (NTLP) of Tanzania. The costs for aNAAT are based on Xpert MTB/RIF hardware and tests as negotiated by FIND [26]. The Xpert MTB/ RIF cost per test is based on the lowest prices quoted and therefore assumes widespread implementation of the technology in the developing world (i.e. $\$ 10.72$ per test which requires global demand to exceed 3.7 million units). If this high usage is not achieved, prices may be as much as $\$ 16.86$ per test. For these reasons the results presented should be treated as indicative of what the modelling approach can deliver rather than definitive forecasts of future absolute costs. The model is configured in such a way that alternative costs for interventions can be evaluated and sensitivity analysis conducted.

\subsection{Patient pathways - individuals with suspected TB}

Patients were categorised when they entered the simulation as either HIV positive or HIV negative and as new suspects or retreatment cases. Retreatment cases have previously been treated for $\mathrm{TB}$, but return with the same symptoms and therefore with a higher probability of being positive for TB and multiple drug resistant TB (MDR-TB). Retreatment cases start TB treatment before all the drug sensitivity results are available due to the life threatening nature of their condition.

Multiple visits by each new patient to the diagnostic centre were modelled. The number of visits for each patient was dependent on a number of factors: the diagnostic test being modelled (note: sputum smear microscopy requires two sputum samples collected on different days including a morning sample in order to enhance the sensitivity for TB diagnosis. ANAAT only requires a single sample); whether the patient returns to the diagnostic centre when required or becomes a diagnostic default; the backlog in the laboratory that could lead to diagnosis not being available on the same
Fig. 3 Schematic of patient and sputum sample pathways

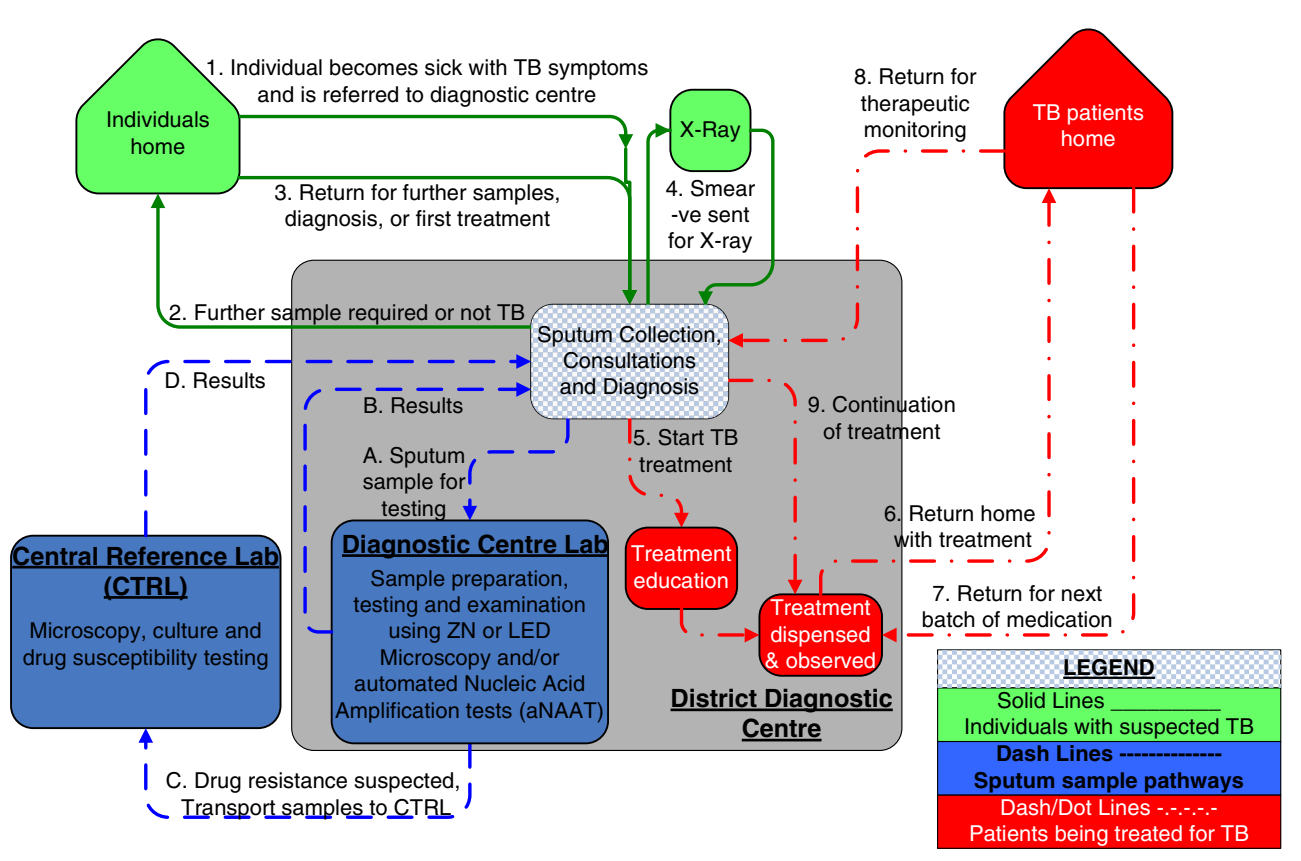


Table 2 Main input parameters to DES

\begin{tabular}{lll}
\hline Input parameter & Description & Source \\
\hline
\end{tabular}

\section{Processing Times}

Diagnostic Centre process times

District and Central laboratory process times

Processing times for aNAAT

\section{Patient Data}

Proportion of smears testing positive

TB cases per year

Number of new patients seeking diagnosis

Arrival time of patients

Proportion of TB cases HIV positive

Retreatment TB Cases per year

Return Probability

Drug resistance levels

\section{Staffing availability}

Staffing in diagnostic district

\section{Diagnostic test Accuracy}

Accuracy of ZN Microscopy.

Accuracy of X-ray and clinical judgement.

Accuracy of optimised smear microscopy

Accuracy of Xpert MTB/RIF

X-ray usage

Proportion of aNAAT tests that give no result

No. of sputum tests required per suspect

\section{Financial Data}

Health System cost data

ZN, LED, X-ray and aNAAT cost

Disability-Adjusted Life Years (DALY's)
Duration of activities within the diagnostic centre for reception, sputum collection, and clinical consultations.

Duration of and batching process for microscopy, culture, and drug sensitivity testing.

The preparation and processing times for aNAAT based on Xpert MTB/RIF.

$\%$ of samples when tested by microscopy result in a positive TB test.

Number of smear positive and smear negative TB cases diagnosed by district.

The number and the arrival rate of individuals seeking diagnosis.

The time during the day that the patient arrives at the diagnostic centre

$\%$ TB cases that are identified as HIV+.

Number of retreatment cases in a diagnostic district.

The probability that an individual returns to the diagnostic centre for the next stage of the diagnostic process.

Proportion of TB cases that are drug resistant.

Number of laboratory and clinical staff by diagnostic district. Shift patterns.

Sensitivity and specificity of ZN Microscopy for TB in sputum samples.

Sensitivity and specificity of clinical judgement after smear negative result.

Sensitivity and specificity of LED fluorescence microscopy.

Sensitivity and specificity of Xpert MTB/RIF in identifying TB from sputum samples.

$\%$ of smear negative TB suspects where an X-ray is requested.

Level of retesting required for Xpert MTB/RIF

The number of sputum samples required for each type of test.

Cost data for staff and drugs for the treatment of TB. Cost per test and investment cost of new technology. Life expectancy and disability weights for TB and HIV
Estimated by management in Tanzania from observations within diagnostic centres.

WHO Global Laboratory Initiative guidelines.

Manufacturer's instructions - Cepheid.

Diagnostic centre laboratory records.

National TB and Leprosy Programme (NTLP) report 2010.

Mean daily numbers calculated from NTLP reports and sampled from Poisson distribution.

Sampled from a user defined distribution that peaks at $45 \mathrm{~min}$ into the working day with all patients arriving by noon.

NTLP annual report 2010

NTLP annual report 2010

Published research [5]

NTLP annual report 2010

Diagnostic centre management

Published research [30]

Published research [28]

WHO policy statement - Fluor-escent lightemitting diode microscopy for diagnosis of TB.

WHO policy statement [11]

Estimated by management in NTLP in Tanzania.

Manufacturers data - Cepheid

NTLP Tanzania

NTLP Tanzania

NTLP in Tanzania and FIND [26]

WHO Country statistics [33]

\section{Treatment Data}

Treatment outcomes

Proportion of TB cases treated that fall into the WHO NTLP annual report 2010 categories of cure, fail, treatment default, death, transfer out.

Treatment times

WHO TB treatment guidelines [25]. 
day as final sputum sample collection; the time the patient was willing to wait in the diagnostic centre for results; whether the initial test result was positive; whether X-ray was required following a negative sputum test; and whether TB treatment would be required (note: if the individual completes diagnosis, a sputum smear positive test result leads to the initiation of TB treatment, called a Smear Positive TB case. A sputum smear negative test result leads to the initiation of TB treatment if the clinician believes mycobacterium tuberculosis is the likely cause of illness, called a Smear Negative TB case. Smear Negative TB diagnoses will usually follow further testing using X-ray and are particularly common where there is high HIV prevalence such as in Tanzania [27, 28]).

\subsection{Patient pathways - individuals being treated for TB}

Once TB has been diagnosed a further visit to the diagnostic centre was modelled to represent the patient's visit with a friend or a member of their family to receive the first batch of medication and for treatment education (note: this process is part of what is known as DOT- Direct Observation of Treatment. DOT is an approach often used for TB treatment. Patients are observed daily taking their medication by a health care worker, friend, or relative to facilitate completion of the full course of treatment).

Patients were modelled returning to the diagnostic centre during treatment for sputum smear microscopy testing after 2 , 5 , and 6 months of treatment. If the test was positive further testing for drug resistance was modelled. If drug resistance was detected the model represented these patients as being diagnosed with MDR-TB by recording this as an outcome of treatment (note: treatment for MDR-TB takes 2 years to complete rather than the $6 \mathrm{~m}$ taken for drug sensitive TB. In Tanzania and much of the developing world MDR-TB currently represents less than $0.5 \%$ of new TB cases). The other treatment outcomes recorded for patients in the model were successful treatment completion; failed treatment (i.e. not cured); or treatment default [25]. Treatment default included patients that die, transfer to another centre, or just do not return for tests and medication during treatment.

\subsection{Sputum sample pathways}

Sputum samples were modelled being collected in the diagnostic centre from individuals suspected of having TB and individuals undergoing treatment for TB. Samples followed a pathway through the district laboratory depending on the patient characteristics, diagnostic technique, and diagnostic algorithm being modelled. There were two very different types of diagnostic test that were simulated. These were microscopy tests which are very labour intensive, and aNAAT which uses machines that can be of varying capacity.
These were therefore modelled separately with control logic defining which test process would be used for which patient sample. This logic enabled a number of different diagnostic algorithms to be evaluated. Samples were modelled being prepared and undergoing testing in the laboratory. This was followed by the examination of the test result. If the test was positive a proportion of samples from individuals suspected of having TB and all the samples from individuals being treated for TB were modelled being sent to the CTRL for drug sensitivity testing (note: drug sensitivity testing can take up to 3 months to complete). In the CTRL samples were modelled being examined through microscopy, culture, and drug sensitivity testing.

\subsection{Outputs}

The outputs from the model were designed to match the requirements that WHO specify for randomised controlled trials of new TB diagnostic technology [29]. These outputs included the laboratory performance, patient diagnosis statistics, and patient treatment outcomes. This information was copied to an Excel spreadsheet for further analysis including calculation of the incremental cost effectiveness ratios (ICER). In addition the diagnostic default rate and the mean time for patients to receive diagnosis were copied to an Excel file to provide the input data required for the linked dynamic epidemiological model.

\section{Model validation and experimentation}

The DES model was validated in two ways. Firstly by working with experienced experts from Tanzania, Malawi, and the Liverpool School of Tropical Medicine to ensure the input parameters, and control logic were working as expected. This involved using the visual display and running through scenarios showing the patient and sample flows. An example of a Witness screen layout for a diagnostic laboratory is shown in Fig. 4. In addition, the model was validated by running for 11 simulated years with input parameters set to mimic the current diagnostic strategies in operation in two diagnostic centres in Tanzania. The two centres were chosen by the NTLP of Tanzania as information was readily available, and different microscopy techniques (ZN and LED) were used at the time of data collection. One centre was from an urban area in Dar es Salaam and the other from a more rural centre in the region of Kilimanjaro. The outputs from the model were validated against the reported results for 2009/2010. A summary from this validation is shown in Table 3.

Experimentation using the DES was conducted to evaluate four example diagnostic algorithms for TB (see Table 4) in the diagnostic centres above. Each algorithm included a different combination of diagnostic tests applied at the different stages 
Fig. 4 Witness screen view for diagnostic laboratory

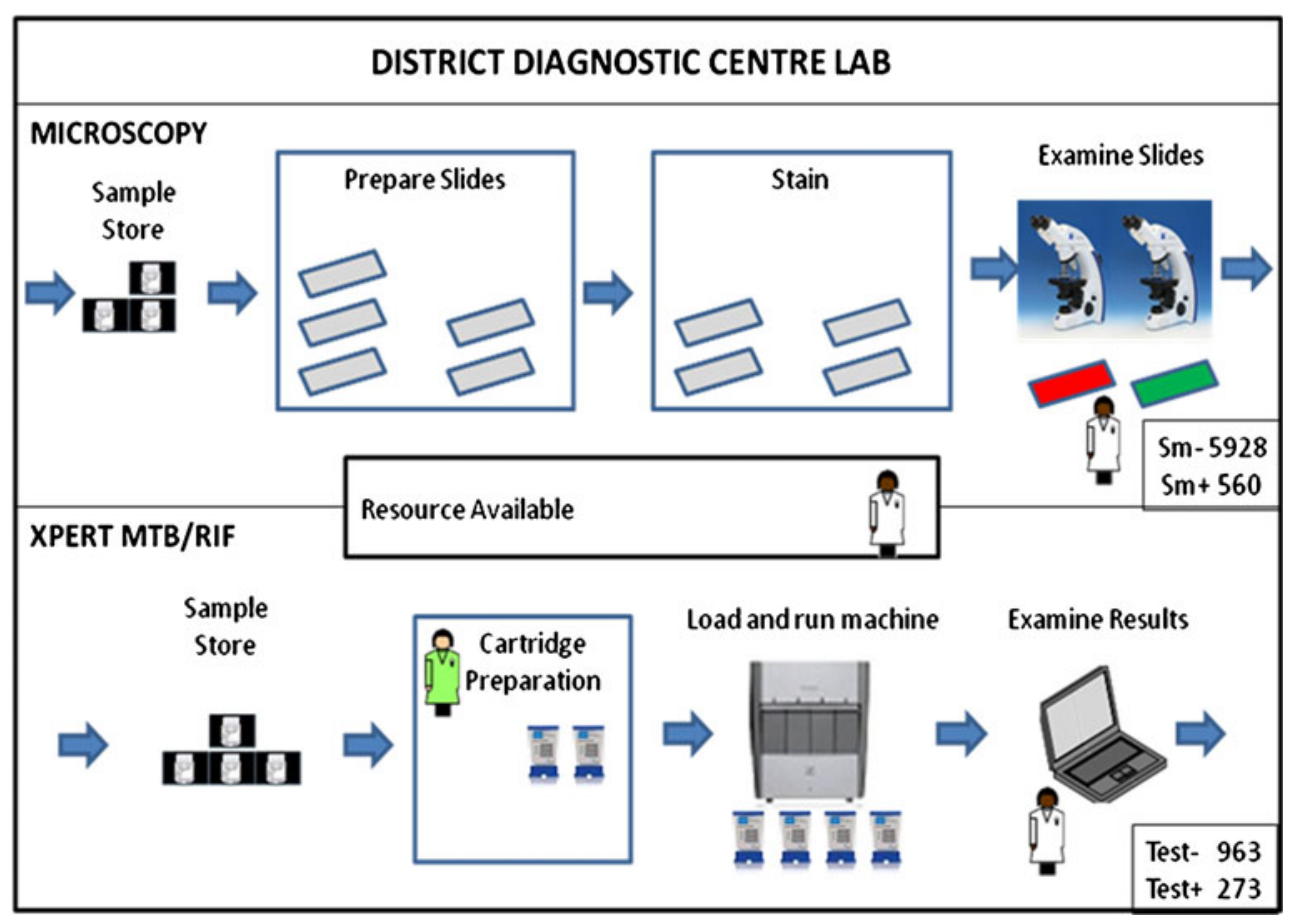

of the TB diagnosis and treatment monitoring process. Option $\mathrm{C}$, which involves a modified algorithm, was added following initial results from the modelling as the NTLP were concerned about the costs of the full roll-out of aNAAT (Option B). The model was run for 11 simulated years for each TB diagnostic option being investigated. 11 years was chosen to allow 1 year for initialisation of the model and then 10 years in order to facilitate the calculation of confidence limits for the outputs.

To test the linkage of the DES with a dynamic epidemiological model, the DES was run for 2 years (first year for initialisation) based on current demand for TB diagnostic services. The diagnostic default rate and the mean time it took for individuals from initially seeking diagnosis to starting appropriate treatment in the second year was exported to an Excel file. This file was then used as input into the epidemiological model. The epidemiological model was then run for 1 year and a forecast of TB incidence produced. This forecast was then used to modify the demand for TB diagnostic services used as an input parameter to the DES. The DES was then run for 1 further year and the diagnostic default rate and the mean time to receive diagnosis exported. These parameters were then fed into the epidemiological model which projected TB incidence for a further year. This process was repeated until 11 years had been modelled. This whole process was repeated twice to model two diagnostic strategies with distinctly different diagnostic default rates, test sensitivities, and laboratory test times. This design enabled the linked approach to be tested and example outputs produced that could indicate the impact of changes in diagnostic performance on TB incidence and prevalence.

Table 3 Validation data

\begin{tabular}{|c|c|c|c|c|c|c|}
\hline Area & Current diagnostic technology & $\begin{array}{l}\text { Means and } 95 \% \\
\text { confidence limits }\end{array}$ & $\begin{array}{l}\text { Smear + ve } \\
\text { TB p.a. }\end{array}$ & $\begin{array}{l}\text { Smear-ve } \\
\text { TB p.a. }\end{array}$ & $\begin{array}{l}\text { Re-treatment } \\
\text { TB p.a. }\end{array}$ & $\begin{array}{l}\mathrm{HIV}+\mathrm{New} \\
\text { Cases p.a. }\end{array}$ \\
\hline \multirow[t]{4}{*}{ Dar es Salaam (Urban) } & \multirow[t]{4}{*}{ ZN Microscopy } & Observed 2009/2010 & 560 & 450 & 93 & 403 \\
\hline & & Modelled Mean & 561.8 & 445.9 & 88.6 & 402.7 \\
\hline & & Lower Limit & 545.2 & 434.3 & 82.5 & 390.6 \\
\hline & & Upper Limit & 578.4 & 457.5 & 94.7 & 414.8 \\
\hline \multirow[t]{4}{*}{ Kilimanjaro (Rural) } & \multirow[t]{4}{*}{ LED Fluorescence Microscopy } & Observed 2009/2010 & 255 & 64 & 91 & 134 \\
\hline & & Modelled Mean & 259.6 & 60.3 & 91.8 & 130.9 \\
\hline & & Lower Limit & 249.5 & 55.4 & 86.0 & 122.5 \\
\hline & & Upper Limit & 269.7 & 65.2 & 97.6 & 139.3 \\
\hline
\end{tabular}


Table 4 TB diagnostic options

\begin{tabular}{|c|c|c|c|c|}
\hline Option & Name & Primary diagnostic tool & Drug Susceptibility Testing (DST) & Treatment monitoring tool \\
\hline Base case & ZN Algorithm & ZN Microscopy with 2 samples & DST in CTRL only & ZN Microscopy \\
\hline $\mathrm{A}$ & LED Algorithm & LED Microscopy with 2 samples & DST in CTRL only & LED Fluorescence Microscopy \\
\hline $\mathrm{B}$ & aNAAT Full Algorithm & Xpert MTB/RIF with 1 sample & $\begin{array}{l}\text { Xpert MTB/RIF in Diagnostic } \\
\text { Centre \& DST in CTRL }\end{array}$ & LED Fluorescence Microscopy \\
\hline $\mathrm{C}$ & aNAAT Partial Algorithm & $\begin{array}{l}\text { Xpert MTB/RIF for HIV+ new cases } \\
\text { and all retreatment cases. } \\
\text { with } 1 \text { sample } \\
\text { \& LED Microscopy for other cases } \\
\text { with } 2 \text { samples }\end{array}$ & $\begin{array}{l}\text { Xpert MTB/RIF in Diagnostic } \\
\text { Centre \& DST in CTRL }\end{array}$ & LED Fluorescence Microscopy \\
\hline
\end{tabular}

\section{Experimental results and evaluation}

5.1 Simulation results based on a large diagnostic centre in Dar es Salaam

Detailed results based on the simulation runs for the large diagnostic centre in Dar es Salaam are shown in Table 5. This table includes a 'patient success rate' which is defined as the proportion of individuals with TB disease who seek diagnosis and are cured. This factor takes into account not only whether patients are put on treatment, but whether they successfully complete treatment and whether they were correctly diagnosed in the first place. The denominator is the number of all individuals seeking diagnosis who have TB disease including those missed by the diagnostic process.

Comparing the performance demonstrates that switching to LED Fluorescence Microscopy (Option A) from ZN Microscopy (Base Case) for this example diagnostic centre would reduce the time to start treatment $(-9 \%)$. This leads to a positive effect on reducing the proportion of diagnostic defaults $(-1.8 \%)$. An increase in the number of smear positive cases detected (+108 per year) is almost fully offset by a reduction in the number of smear negative cases $(-91$ per year). This means there is no significant increase in the number of patients started on TB treatment. However, a reduction in the number of individuals incorrectly put on TB treatment (false positives $-2.8 \%$ ) as a result of smear negative clinical diagnosis, results in a significant increase in the number of patients cured $(+5.0 \%)$. This takes the patient success rate to nearly $70 \%$. This is achieved with minimal increase in running costs for a low investment of around $\$ 2,300$.

A full rollout of aNAAT (Option B) for diagnosis has a greater impact. Comparing full aNAAT rollout using Xpert MTB/RIF with ZN Microscopy (the base case) shows a large reduction in the time to start treatment from a mean of 24.8 days to 15.0 days (-39\%) and mean patient visits required from 6.0 to 3.7 . These improvements result in a reduction in the proportion of diagnostic defaults $(-5.0 \%)$. An increase in the number of test positive cases detected $(+499$ per year) is partly offset by a reduction in the number of test negative cases ( -393 per year). This leads to a significant increase in the overall number of patients started on TB treatment $(+10.5 \%)$ and reduces the false positive rate $(-5.6 \%)$. An increase in the number of patients cured by $15.8 \%$ takes the patient success rate to over $77 \%$. Because Xpert MTB/RIF detects resistance to one of the key TB drugs (Rifampicin) at initial diagnosis; there is also a significant increase in MDR-TB cases detected $(+2.9$ per year). This leads to drug resistant cases starting on effective treatment earlier. To achieve these results requires investment of $\$ 34,700$ and a significant increase in running costs of around $\$ 46,800$ per year for this diagnostic centre.

The fourth option (Option C) looks at a lower cost implementation of aNAAT by targeting the new technology only at $\mathrm{HIV}+$ cases where it is known the incremental effect is more significant as the base case technology has particularly low sensitivity for HIV+ individuals suspected of having TB [30]. Compared to Option B this reduces the impact, but still delivers significant improvements over the base case. A reduction in the time to start treatment from a mean of 24.8 days to 18.6 days $(-25 \%)$ and mean patient visits required from 6.0 to 3.8 has a positive effect on reducing the proportion of diagnostic defaults $(-5.0 \%)$. An increase in the number of test positive cases detected ( +337 per year) is partly offset by a reduction in the number of test negative cases ( -258 per year). This leads to a significant increase in the number of patients started on TB treatment $(+7.7 \%)$ and reduces the false positive rate $(-5.0 \%)$. An increase in the number of patients cured by around $10.8 \%$ takes the patient success rate to $73.6 \%$. To achieve this requires investment of $\$ 19,300$ (\$15,400 less than full aNAAT rollout) and increased running costs of $\$ 25,600$ per year (\$21,200 per year less than full aNAAT rollout).

For this example diagnostic centre, the results in Table 5 show that all of the options can be delivered with no change 
Table 5 Results from health system model for a diagnostic centre in Dar es Salaam

\begin{tabular}{|c|c|c|c|c|c|c|c|}
\hline & \multicolumn{4}{|l|}{ Performance } & \multicolumn{3}{|c|}{ Difference to base case } \\
\hline & Base Case ZN & A LED Micro & B aNAAT Full & $\mathrm{C}$ aNAAT Part & $\begin{array}{l}\text { A LED } \\
\text { Micro }\end{array}$ & $\begin{array}{l}\text { B } \\
\text { aNAAT } \\
\text { Full }\end{array}$ & $\begin{array}{l}\mathrm{C} \\
\text { aNAAT } \\
\text { Part }\end{array}$ \\
\hline \multicolumn{8}{|l|}{ Diagnosis } \\
\hline $\begin{array}{l}\text { Mean Time to } \\
\text { treatment (days) }\end{array}$ & $24.8(24.7-24.9)$ & $22.5(22.4-22.6) *$ & $15.0(14.9-15.1)$ * & $18.6(18.5-18.7) *$ & $-9 \%$ & $-39 \%$ & $-25 \%$ \\
\hline $\begin{array}{l}\text { Mean No. of } \\
\text { visits/patient }\end{array}$ & $6.0(5.9-6.1)$ & $4.5(4.4-4.6) *$ & $3.7(3.6-3.7) *$ & $3.8(3.7-3.8) *$ & $-25 \%$ & $-38 \%$ & $-37 \%$ \\
\hline Test + ve TB case/yr & $562(545-578)$ & $670(648-691) *$ & $1060(1041-1079) *$ & $898(882-915) *$ & +108 & +499 & +337 \\
\hline Test -ve TB case/yr & $446(434-458)$ & $355(343-367) *$ & $53(48-57) *$ & $188(178-197) *$ & -91 & -393 & -258 \\
\hline $\begin{array}{l}\text { Total TB treatment } \\
\text { cases } / \mathrm{yr}\end{array}$ & $1008(988-1028)$ & $1025(1002-1048)$ & $1113(1093-1133)$ * & $1086(1068-1103) *$ & $1.7 \%$ & $10.5 \%$ & $7.7 \%$ \\
\hline MDR-TB Cases/yr & $3.7(2.4-5.0)$ & $3.5(2.2-4.8)$ & $6.6(5.0-8.2) *$ & $4.6(3.1-6.1)$ & -0.2 & +2.9 & +0.9 \\
\hline Samples/yr (,000’s) & 14.3 & 14.2 & 9.1 & 12.1 & $-1 \%$ & $-36 \%$ & $-15 \%$ \\
\hline$\%$ Initial default & $15.7 \%(15.5-15.9)$ & $13.9 \%(13.6-14.2) *$ & $10.7 \%(10.5-11.0) *$ & $10.7 \%(10.5-10.9) *$ & $-1.8 \%$ & $-5.0 \%$ & $-5.0 \%$ \\
\hline \multicolumn{8}{|l|}{ Treatment } \\
\hline $\begin{array}{l}\text { Patients Cured } \\
\text { p.a. }^{\text {a }}(95 \% \text { C.I. })\end{array}$ & $842(827-858)$ & $884(866-902) *$ & $975(955-995) *$ & $933(917-948)$ * & $5.0 \%$ & $15.8 \%$ & $10.8 \%$ \\
\hline False + Rate for $\mathrm{TB}$ & $14.3 \%$ & $11.5 \%$ & $8.7 \%$ & $9.3 \%$ & $-2.8 \%$ & $-5.6 \%$ & $-5.0 \%$ \\
\hline \multicolumn{8}{|l|}{ Staffing } \\
\hline No.lab staff & 2 & 2 & 2 & 2 & 0 & 0 & 0 \\
\hline Utilization & $79 \%$ & $48 \%$ & $18 \%$ & $37 \%$ & $-31 \%$ & $-61 \%$ & $-42 \%$ \\
\hline \multicolumn{8}{|l|}{ Costs } \\
\hline $\begin{array}{c}\text { Incremental } \\
\text { Cost/yr \$k } \\
\text { (95\% C.I.) }\end{array}$ & $95.2(90.2-100.3)$ & $95.3(90.3-100.2)$ & $142.0(137.6-147.3) *$ & $120.8(115.4-126.2) *$ & +0.0 & +46.8 & +25.6 \\
\hline Investment Cost $\$ \mathrm{k}$ & 0.0 & 2.3 & 34.7 & 19.3 & +2.3 & +34.7 & +19.3 \\
\hline \multicolumn{8}{|l|}{ Summary } \\
\hline Patient Success ${ }^{\mathrm{b}}$ & $66.6 \%(65.3-67.8)$ & $69.5 \%(68.0-70.9) *$ & $77.2 \%(75.6-78.8) *$ & $73.6 \%(72.4-74.9) *$ & $+2.9 \%$ & $+10.6 \%$ & $+7.1 \%$ \\
\hline
\end{tabular}

$95 \%$ confidence limits for the means in brackets

* - significantly different from base case at $95 \%$ level

${ }^{a}$ Patients cured excludes false positives who received treatment but had no TB disease

${ }^{\mathrm{b}}$ Patient success is the $\%$ of individuals with TB that seek diagnosis and are cured

in laboratory staffing levels. Staff utilization falls by between $31 \%$ and $61 \%$ depending on the new test employed. A diagnostic centre of this size requires a minimum of 2 trained laboratory staff to cover for sickness, training, and holiday. So, although laboratory staff utilization is reduced by introducing the new aNAAT test, there is unlikely to be any cost saving, however there is an opportunity for staff to be employed in other non TB diagnosis activities.

\subsection{Incremental cost effectiveness ratios (ICER)}

In order for policy makers to decide which of the available options to implement, they need to understand the costs versus benefits of each option and to be able to compare these to other potential demands on resources. Table 6 includes an illustrative example of an assessment of incremental cost effectiveness ratios (ICER). These are based on the incremental health system costs per 'Disability adjusted life year' (DALY) averted, as defined by the WHO [31, 32]. The calculations use data on life expectancy and disability weights from the WHO Global Health Observatory [33]. For this analysis, incremental health system costs include both the additional annual running costs (i.e. consumables, drugs, staffing, X-rays, and equipment maintenance) and the investment costs (i.e. microscopes, aNAAT equipment, and computer equipment) discounted over 5 years at $5 \%$ per 
Table 6 Illustrative summary results on incremental cost effectiveness ratios

\begin{tabular}{|c|c|c|c|c|}
\hline Area & Difference to base case & A LED micro. & B aNAAT full & $\mathrm{C}$ aNAAT partial \\
\hline \multirow[t]{6}{*}{ Dar es Salaam (Urban) } & Incremental TB Patients cured per year & 42 & 133 & 91 \\
\hline & $\%$ increase in patients cured & $+5.0 \%$ & $+15.8 \%$ & $+10.8 \%$ \\
\hline & Incremental DALY averted/year & $399(259-539)$ & $1,220(1011-1429) *$ & $843(655-1032) *$ \\
\hline & Incremental Health System costs/year (\$k) & 0.5 & 53.3 & 29.2 \\
\hline & Incremental costs/DALY averted (ICER) (\$) & $1.2(0.75-1.57)$ & $43.6(36.1-51.0)$ & $34.5(26.8-42.2)$ \\
\hline & $\begin{array}{l}\text { Sensitivity of ICER to aNAAT cost per test } \$ 16.9 \\
\text { rather than } \$ 10.7\end{array}$ & $\mathrm{n} / \mathrm{a}$ & $73.4(60.8-85.9)$ & $52.8(41.0-64.6)$ \\
\hline \multirow[t]{6}{*}{ Kilimanjaro (Rural) } & Incremental TB Patients cured per year & $\mathrm{n} / \mathrm{a}$ & 85 & 48 \\
\hline & $\%$ increase in patients cured & & $+25.3 \%$ & $+14.4 \%$ \\
\hline & Incremental DALY averted/year & $\mathrm{n} / \mathrm{a}$ & $763(663-864) *$ & $434(338-531) *$ \\
\hline & Incremental Health System costs/year (\$k) & $\mathrm{n} / \mathrm{a}$ & 26.0 & 18.8 \\
\hline & Incremental costs/DALY averted (ICER) (\$) & $\mathrm{n} / \mathrm{a}$ & $34.0(29.5-38.5)$ & $43.1(33.5-52.8)$ \\
\hline & $\begin{array}{l}\text { Sensitivity of ICER to aNAAT cost per test } \$ 16.9 \\
\text { rather than } \$ 10.7\end{array}$ & $\mathrm{n} / \mathrm{a}$ & $55.6(48.3-62.9)$ & $59.1(46.0-72.3)$ \\
\hline
\end{tabular}

$95 \%$ confidence limits for the means in brackets

* - significantly different from base case at $95 \%$ level

annum (the period and rate have been chosen to represent a cautious view on the resilience of the technology in an African setting). Summary results from the modelling are presented for both the diagnostic centre in Dar es Salaam and for the more rural setting in the Kilimanjaro area where the base case is LED fluorescence rather than $\mathrm{ZN}$ microscopy. These results are indicative and suggest the ICER based on DALY's averted is minimal for LED Fluorescence microscopy, but more significant for the aNAAT strategies and therefore needs to be compared to other potential interventions in the health service in Tanzania before progressing. The ICER could also be compared to a country specific willingness to pay threshold such as Gross Domestic Product (GDP) per capita or other alternative thresholds as discussed in Shillcutt, et al. [34]. In this illustrative analysis a low threshold of $\$ 150$ has been used as proposed by the World Bank for low income countries like Tanzania [35]. With a threshold of $\$ 150$ per DALY averted all these interventions on their own would be considered cost effective. Sensitivity analysis on the cost per test in Table 6 shows even when costs per test rises to $\$ 16.86$ these interventions fall well below a ceiling of $\$ 150$ per DALY averted.

\subsection{Deciding between potential combinations of interventions}

ICER is a vital criterion that the Ministry of Health would consider in making their decision, but it is not the only criterion. For example, the sustainability of the intervention would also be essential. To illustrate how the outputs from the model might be used to decide between potential interventions, taking account of sustainability and the threshold ICER, all relevant combinations of intervention from this study for the two districts modelled have been listed in
Table 7. The interventions have been ranked by the impact on health system costs from highest to lowest. The table shows for each potential combination of interventions, the projected impact on DALY's, the incremental health system costs, the ICER of the intervention compared to base case, and the ICER compared to the next most effective intervention that is less costly. Some combinations of intervention are ineffective because there are other combinations that are both more beneficial and less expensive e.g. implementation of partial aNAAT at Dar es Salaam on its own (row 6) is more expensive and less beneficial than combining LED in Dar es Salaam and full aNAAT at Kilimanjaro (row 7). Assuming an ICER threshold of $\$ 150$ for an intervention to be cost effective leads to some other interventions being classified as incrementally ineffective. For example, the ICER of implementing full aNAAT in Dar es Salaam combined with partial aNAAT in Kilimanjaro (row 2), compared to implementing partial aNAAT in Dar es Salaam combined with full aNAAT in Kilimanjaro (row 3), is $\$ 362$ and therefore is not incrementally effective. Table 7 also shows which combinations of interventions provide best value for money at differing levels of commitment to future incremental spend. For example, if $\$ 30,000$ per year is the sustainable incremental level of spend, then the best combination of interventions is LED microscopy in Dar es Salaam combined with full aNAAT in Kilimanjaro (row 7).

5.4 Results from linking the DES with a dynamic epidemiological model

Selected inputs and outputs from the test of linking the DES with a dynamic epidemiological model are shown in Table 8 . 
Table 7 Ranked results for combined TB interventions in Dar es Salaam and Kilimanjaro

\begin{tabular}{|c|c|c|c|c|c|c|}
\hline $\begin{array}{c}\text { Rank } \\
\text { No. by } \\
\text { cost } \\
\text { (High- } \\
\text { Low) }\end{array}$ & $\begin{array}{l}\text { Combination } \\
\quad \text { of } \\
\text { interventions }\end{array}$ & $\begin{array}{c}\text { Incremental } \\
\text { Health } \\
\text { System } \\
\text { Costs }(\$ k) \\
\text { per year }\end{array}$ & $\begin{array}{c}\text { DALY's } \\
\text { averted } \\
\text { per year }\end{array}$ & $\begin{array}{l}\text { ICER } \\
\text { to } \\
\text { base } \\
\text { case }\end{array}$ & $\begin{array}{l}\text { ICER(2) } \\
\text { to the next } \\
\text { effective } \\
\text { intervention } \\
\text { that is less } \\
\text { costly }\end{array}$ & $\begin{array}{c}\text { Comment } \\
\text { (ICER } \\
\text { threshold of } \\
\$ 150)\end{array}$ \\
\hline 1 & $\begin{array}{l}\text { Dar es Salaam } \\
\text { - Full aNAAT } \\
\text { Kilimanjaro } \\
\text { - Full aNAAT }\end{array}$ & 79.3 & 1,983 & 40.0 & 65.1 & $\begin{array}{c}\text { Cost } \\
\text { effective } \\
\$ 79.3 \mathrm{k} \mathrm{pa} \\
\text { required }\end{array}$ \\
\hline 2 & $\begin{array}{l}\text { Dar es Salaam } \\
\text { - Full aNAAT } \\
\text { Kilimanjaro } \\
\text { - Part. aNAAT }\end{array}$ & 72.1 & 1,654 & 43.6 & 361.8 & $\begin{array}{l}\text { Ineffective } \\
\text { due to high } \\
\text { ICER(2) }\end{array}$ \\
\hline 3 & $\begin{array}{l}\text { Dar es Salaam } \\
\text { - Part. aNAAT } \\
\text { Kilimanjaro } \\
\text { - Full aNAAT }\end{array}$ & 54.7 & 1,606 & 34.0 & 63.5 & $\begin{array}{c}\text { Cost } \\
\text { effective } \\
\$ 54.7 \mathrm{pa} \\
\text { required }\end{array}$ \\
\hline 4 & $\begin{array}{l}\text { Dar es Salaam } \\
\text { - Full aNAAT } \\
\text { Kilimanjaro } \\
\text { - Do Nothing }\end{array}$ & 53.3 & 1220 & 43.6 & & $\begin{array}{c}\text { Ineffective } \\
\text { due to no } \\
\text { benefit over } \\
\text { No.5 }\end{array}$ \\
\hline 5 & $\begin{array}{l}\text { Dar es Salaam } \\
\text { - Part. aNAAT } \\
\text { Kilimanjaro } \\
\text { - Part. aNAAT }\end{array}$ & 47.9 & 1,277 & 37.5 & 185.8 & $\begin{array}{l}\text { Ineffective } \\
\text { due to high } \\
\text { ICER(2) }\end{array}$ \\
\hline 6 & $\begin{array}{l}\text { Dar es Salaam } \\
\text { - Part. aNAAT } \\
\text { Kilimanjaro } \\
\text { - Do Nothing }\end{array}$ & 29.1 & 843 & 34.5 & & $\begin{array}{c}\text { Ineffective } \\
\text { due to no } \\
\text { benefit over } \\
\text { No.7 }\end{array}$ \\
\hline 7 & $\begin{array}{l}\text { Dar es Salaam } \\
\text { - LED Micro } \\
\text { Kilimanjaro } \\
\text { - Full aNAAT }\end{array}$ & 26.5 & 1,162 & 22.8 & 21.9 & $\begin{array}{c}\text { Cost } \\
\text { effective } \\
\$ 26.5 \mathrm{pa} \\
\text { required }\end{array}$ \\
\hline 8 & $\begin{array}{l}\text { Dar es Salaam } \\
\text { - LED Micro } \\
\text { Kilimanjaro } \\
\text { - Part. aNAAT }\end{array}$ & 19.3 & 833 & 23.1 & 43.3 & $\begin{array}{c}\text { Cost } \\
\text { effective } \\
\$ 19.3 \mathrm{pa} \\
\text { required }\end{array}$ \\
\hline 9 & $\begin{array}{l}\text { Dar es Salaam } \\
\text { - LED Micro } \\
\text { Kilimanjaro } \\
\text { - Do Nothing }\end{array}$ & 0.5 & 399 & 1.2 & 1.2 & $\begin{array}{c}\text { Cost } \\
\text { effective } \\
\$ 0.5 \mathrm{pa} \\
\text { required }\end{array}$ \\
\hline
\end{tabular}

These indicative results demonstrate that when the diagnostic strategy is changed there can be significant impact on TB incidence. In the example in Table 8 two diagnostic strategies are compared. Strategy 1: test sensitivity $50 \%$ and mean time to receive diagnosis 4.3 days, compared to Strategy 2: test sensitivity increased to $65 \%$ and mean time to receive diagnosis decreased to 1.7 days. The result of such a change leads to a reduction in TB incidence after 10 years of $6 \%$. These results illustrate how transmission modelling can be linked to DES and enhance understanding of impacts [36].

\section{Discussion and further research}

The results of the simulation demonstrate that DES can provide useful projections of the effects on the health system, running costs, and patient outcomes of alternative TB 
Table 8 Selected inputs/outputs from linking the DES with an epidemiological model

\begin{tabular}{|c|c|c|c|c|c|c|}
\hline \multicolumn{7}{|c|}{ Operational Component - Discrete Event Simulation } \\
\hline & \multicolumn{3}{|c|}{ Input } & \multicolumn{3}{|c|}{ Output } \\
\hline & \multicolumn{3}{|c|}{$\begin{array}{l}\text { Mean daily demand for } \\
\text { diagnosis per centre }\end{array}$} & \multicolumn{3}{|c|}{ Mean days to receive diagnosis } \\
\hline $\begin{array}{c}\text { Strategy } 1 \\
\text { Strategy } 2 \\
\quad \#\end{array}$ & $\begin{array}{c}\text { Year } 1 \\
15.0 \\
15.0 \\
(0 \%)\end{array}$ & $\begin{array}{c}\text { Year } 5 \\
13.5 \\
13.0 \\
(-4 \%)\end{array}$ & $\begin{array}{c}\text { Year } 10 \\
12.2 \\
11.5 \\
(-6 \%)\end{array}$ & $\begin{array}{c}\text { Year } 1 \\
4.3 \\
1.7 \\
(-60 \%)\end{array}$ & $\begin{array}{c}\text { Year } 5 \\
4.1 \\
1.7 \\
(-59 \%)\end{array}$ & $\begin{array}{c}\text { Year } 10 \\
4.2 \\
1.6 \\
(-61 \%)\end{array}$ \\
\hline \multirow[b]{2}{*}{$\begin{array}{l}\text { Strategy } 1 \\
\text { Strategy } 2\end{array}$} & \multicolumn{3}{|c|}{ Test sensitivity for TB } & \multicolumn{3}{|c|}{ Diagnostic default\% } \\
\hline & $\begin{array}{c}\text { Year } 1 \\
50 \% \\
65 \%\end{array}$ & $\begin{array}{c}\text { Year } 5 \\
50 \% \\
65 \% \\
\end{array}$ & $\begin{array}{c}\text { Year TO } \\
50 \% \\
65 \%\end{array}$ & $\begin{array}{c}\text { Year } 1 \\
6.0 \\
0.1\end{array}$ & $\begin{array}{c}\text { Year } 5 \\
6.3 \\
0.0\end{array}$ & $\begin{array}{c}\text { Year } 10 \\
6.2 \\
0.0\end{array}$ \\
\hline & \multicolumn{3}{|c|}{$\begin{array}{l}\text { Laboratory time per sample } \\
\text { (minutes.) }\end{array}$} & \multicolumn{3}{|c|}{$\begin{array}{c}\text { Mean daily patients starting } \mathrm{TB} \\
\text { treatment per centre }\end{array}$} \\
\hline $\begin{array}{c}\text { Strategy } 1 \\
\text { Strategy } 2 \\
\#\end{array}$ & $\begin{array}{c}\text { Year } 1 \\
15 \\
5 \\
(-67 \%)\end{array}$ & $\begin{array}{c}\text { Year } 5 \\
15 \\
5 \\
(-67 \%)\end{array}$ & $\begin{array}{c}\text { Year } 10 \\
15 \\
5 \\
(-67 \%)\end{array}$ & $\begin{array}{c}\text { Year } 1 \\
3.6 \\
4.2 \\
(+17 \%)\end{array}$ & $\begin{array}{c}\text { Year } 5 \\
3.0 \\
3.6 \\
(+21 \%)\end{array}$ & $\begin{array}{c}\text { Year } 10 \\
2.9 \\
3.5 \\
(+20 \%)\end{array}$ \\
\hline \multicolumn{7}{|c|}{ Disease Transmission Component - Dynamic Epidemiological Model } \\
\hline & \multicolumn{3}{|c|}{ Output } & \multicolumn{3}{|c|}{ Input } \\
\hline & \multicolumn{3}{|c|}{ TB Incidence (per 100,000) } & \multicolumn{3}{|c|}{ Diagnostic Default $\%$} \\
\hline $\begin{array}{c}\text { Strategy } 1 \\
\text { Strategy } 2 \\
\#\end{array}$ & $\begin{array}{c}\text { Year } 1 \\
113 \\
112 \\
(-1 \%)\end{array}$ & $\begin{array}{c}\text { Year 5 } \\
103 \\
100 \\
(-3 \%)\end{array}$ & $\begin{array}{c}\text { Year } 10 \\
93 \\
87 \\
(-6 \%)\end{array}$ & $\begin{array}{c}\text { Year } 1 \\
6.0 \\
0.1 \\
\end{array}$ & $\begin{array}{c}\text { Year } 5 \\
6.3 \\
0.0\end{array}$ & $\begin{array}{c}\text { Year } 10 \\
6.2 \\
0.0\end{array}$ \\
\hline \multirow[b]{2}{*}{$\begin{array}{c}\text { Strategy } 1 \\
\text { Strategy } 2 \\
\quad \#\end{array}$} & \multicolumn{3}{|c|}{ TB Prevalence (per 100,000) } & \multicolumn{3}{|c|}{ Mean days to receive diagnosis } \\
\hline & $\begin{array}{c}\text { Year } 1 \\
172 \\
160 \\
(-7 \%)\end{array}$ & $\begin{array}{c}\text { Year 5 } \\
143 \\
122 \\
(-15 \%)\end{array}$ & $\begin{array}{c}\text { Year } 10 \\
118 \\
99 \\
(-16 \%)\end{array}$ & $\begin{array}{c}\text { Year } 1 \\
4.3 \\
1.7 \\
(-60 \%)\end{array}$ & $\begin{array}{c}\text { Year } 5 \\
4.1 \\
1.7 \\
(-59 \%)\end{array}$ & $\begin{array}{c}\text { Year } 10 \\
4.2 \\
1.6 \\
(-61 \%)\end{array}$ \\
\hline \multicolumn{7}{|c|}{ \# The percent is the relative difference comparing strategy 2 to strategy 1} \\
\hline & & $\begin{array}{l}\text { e Intern } \\
\text { Copyri }\end{array}$ & $\begin{array}{l}1 \text { Unior } \\
\text { The U }\end{array}$ & $\begin{array}{l}\text { inst Tt } \\
36]\end{array}$ & s & Diseas \\
\hline
\end{tabular}

diagnostic strategies in the diagnostic centres of Tanzania. From these results it can be concluded that in the centre in Dar es Salaam significant improvements in TB diagnosis can be delivered through optimising sputum smear microscopy by implementing LED Fluorescence microscopes. In this resource constrained setting, an estimated $5.0 \%$ increase in TB cures could be delivered at very low investment. If more resources are available, implementation of aNAAT can be a cost effective approach in both Dar es Salaam and Kilimanjaro. The model demonstrates that the benefit of aNAAT in the number of patients cured is up to $15.8 \%$ in Dar es Salaam and $25.3 \%$ in the Kilimanjaro area. These benefits accrue not just from an increase in the number of patients started on TB treatment, but also from earlier case detection, a reduced diagnostic default rate, and a reduction in false positive diagnoses. Comparing results between the 2 diagnostic centres indicates that the benefits and cost effectiveness vary between settings. When resources are scarce the results from the modelling can help policy makers prioritise locations and the type of intervention.

\subsection{Scale-up in Tanzania}

Using the interactivity and flexibility of the DES modelling approach makes it possible for TB policy makers to explore future interventions and different contexts without major model redevelopment. This utility has been recognised by 
policy makers in Tanzania who are now considering specific sites and algorithms for trial of the new aNAAT technology. These trial sites will be modelled and alternative diagnostic algorithms investigated. In particular, a new lower cost algorithm involving aNAAT will be explored. This intervention will use aNAAT as an additional (rather than replacement) tool to smear microscopy for new suspected TB cases. Only suspects who are sputum smear negative and HIV positive will be tested using aNAAT. The results of the modelling will feed into the implementation trial and help validate the approach, thereby improving its effectiveness for future applications.

There are a number of further applications of the DES model that are of interest and should be explored. The model should be used to make an overall assessment of the impacts of scale up of alternative algorithms using aNAAT across the whole of Tanzania which should be designed to project the impacts across the 168 diagnostic districts simultaneously using the DES with periodic links to the disease transmission component. One approach being considered is the identification and inclusion in a single model of a sample of diagnostic facilities which would be representative of districts with different capacity, HIV and TB prevalence. These results could then be factored up proportionately to represent the whole country.

Policy advisers in Tanzania have requested the ability to be able to use the DES themselves to evaluate alternative diagnostic strategies in the future. A pilot study in Tanzania supported by the authors will demonstrate whether the models are sufficiently user friendly or whether further development will be necessary. The policy advisers will be trained to use the developed model to evaluate current TB diagnostic technology against the new tools and alternative algorithms for a sample of diagnostic districts. This will require the developed model to be implemented on hardware in Tanzania and data collected and loaded by Tanzanian staff for each diagnostic district that is to be evaluated. Evaluation of the impacts can then take place by local policy advisors using the model. Development of the DES will not be required by the staff in Tanzania.

\subsection{Generic models and other applications}

The DES has been developed as a flexible model based on the knowledge of TB diagnostic processes in Tanzania and Malawi. The flexibility incorporated allows many parameters to be varied (Table 2) including patient demand and profiles as well as alternative diagnostic tools and algorithms for investigation. However, even though most developing countries follow the recommended TB diagnostic algorithms of the World Health Organisation, it is likely that some modifications would be required to represent some other countries. These modifications are expected to be principally in relation to the level of centralisation of TB services. Centralisation affects patient pathways, and the impact of the requirements for drug sensitivity testing, particularly for countries where multi drug resistant TB (MDRTB) is a greater burden (e.g. South Africa). Further research is necessary to see whether the flexibility to cover these differences can be incorporated into a generic model that could then be used for TB diagnostics across the developing world or whether a small suite of models is necessary to cover each type of context.

The DES approach may also have benefits in helping national TB programmes assess diagnostic tools used in central reference facilities for diagnosis of MDR-TB. There are many new tools now available including Xpert MTB/ RIF, Line Probe Assay, and liquid culture e.g. MGIT [37]. The authors plan to investigate the use of DES during involvement in a pragmatic trial of these options in central TB facilities in Brazil.

\section{Conclusion}

A health system modelling approach using a discrete-event simulation (DES) tool can provide information to help policy makers understand context-specific impacts in resourceconstrained settings and make decisions on TB diagnostic tools. The DES can, and where possible should, be linked to a disease transmission component to enhance predictions and to provide outputs on important factors such as TB incidence which will in turn impact health system and patient outcomes. A visual and interactive modelling tool enables national policy makers to assist in validation, identify new strategies to investigate, and engage with the outputs. Further research is needed to prove the approach across a wider range of developing countries and then to actively use the approach to assist in making the important decisions about the options that leaders of national TB programmes are currently considering. These decisions are urgent and have the potential to make a highly significant and beneficial impact on worldwide TB control in the coming years.

Acknowledgments The research is part of the TREAT TB initiative funded by USAID and led by the International Union Against Tuberculosis and Lung Disease (The Union). Table 8 has been reprinted with permission from The Union - Copyright (C) The Union [36]. The authors thank C Hanson and Y Mukadi of USAID for their support and direction. The initial prototype models were developed by $\mathrm{G}$ Potadar and $\mathrm{H} \mathrm{Lu}$, students of the University of Liverpool who were supervised by Dr. H Ismail. The authors thank Dr S Egwaga, Program Director for the National TB and Leprosy Program (NTLP) in Tanzania, for his support. Essential to the modelling has been the work of R Shirima of the NTLP who has provided much of the data. This document has been produced thanks to a grant from USAID. The contents of this document are the sole responsibility of the authors and can under no circumstances be regarded as reflecting the positions of The Union, nor those of its Donors. 
Open Access This article is distributed under the terms of the Creative Commons Attribution License which permits any use, distribution, and reproduction in any medium, provided the original author(s) and the source are credited.

\section{References}

1. World Health Organisation World TB Control (2011) http:// www.who.int/tb/publications/global_report/2011/gtbr11_full.pdf http://www.who.int/mediacentre/factsheets/fs104/en/

2. Stop TB Partnership (2009) The Global Plan to Stop TB 2011-2015 Progress Report 2006-2008 http://www.stoptb.org/assets/documents/ global/plan/The_global_plan_progress_report1.pdf

3. Kemp JR, Mann G, Simwaka BN, Salaniponi FM, Squire SB (2007) Can Malawi's poor afford free tuberculosis services? Patient and household costs associated with a tuberculosis diagnosis in Lilongwe. Bull World Health Organ 85(8):580-585

4. Liu X, Thomson R, Gong Y, Zhao F, Squire SB, Tolhurst R, Zhoa $X$, Yan F, Tang S (2007) How affordable are tuberculosis and treatment in rural China? Trop Med Int Health 12. doi:10.111/ j.1365-3156.2007.01953.x

5. Squire SB, Belaye AK, Kashoti A, Salaniponi FM, Mundy CJ, Theobald S et al (2005) 'Lost' smear-positive pulmonary tuberculosis cases: where are they and why did we lose them? Int J Tuberc Lung Dis 9(1):25-31

6. Marais BJ, Brittle W, Painczyk K, Hesseling AC, Beyers N, Wasserman E et al (2008) Use of light-emitting diode fluorescence microscopy to detect acid-fast bacilli in sputum. Clin Infect Dis 47 (2):203-207

7. Boehme CC, Nabeta P, Hillemann D, Nicol MP, Shenai S, Krapp F et al (2010) Rapid molecular detection of tuberculosis and rifampin resistance. N Engl J Med 363(11):1005-1015

8. Morgan M, Kalantri S, Flores L, Pai M (2005) A commercial line probe assay for the rapid detection of rifampicin resistance in Mycobacterium tuberculosis: a systematic review and metaanalysis. BMC Infect Dis 5:62

9. Ramsay A, Yassin MA, Cambanis A, Hirao S, Almotawa A, Gammo M et al (2009) Front-loading sputum microscopy services: an opportunity to optimise smear-based case detection of tuberculosis in high prevalence countries. J Trop Med 2009:398767

10. Small PM, Pai M (2010) Tuberculosis diagnosis - time for a game change. N Engl J Med 363(11):1070-1071

11. World Health Organization (2011) WHO endorses new rapid tuberculosis test. http://www.who.int/tb/laboratory/new_rapid_test/ en/index.html

12. Squire SB, Ramsay A, Van den Hof S, Millington K, Langley I, Bello G, Kritski A, Detjen A, Thomson R, Cobelens F, Mann G (2011) Making innovations accessible to the poor through implementation by research. Int $\mathrm{J}$ Tuberc Lung Dis 15(7):1-9. doi:10.5588/ijtld.11.0161

13. Mann G, Squire SB, Bissell K, Eliseev P, Du Toit E, Hesseling A et al (2010) Beyond accuracy: creating a comprehensive evidence base for TB diagnostic tools. Int J Tuberc Lung Dis 14(12):15181524

14. Kapsali M, Bolt T, Bayer S, Brailsford S (2010) The simulation model as an object between boundaries, Proceedings HaCIRIC International Conference

15. Katsaliaki K, Mustafee N (2011) Applications of simulation within the healthcare context. J Oper Res Soc 201162:1431-1451

16. Günal M, Pidd M (2010) Discrete event simulation for performance modelling in health care: a review of the literature. J Simul 4:42-51
17. Reynolds M, Vasilakis C et al (2011) Using discrete event simulation to design a more efficient hospital pharmacy for outpatients. Health Care Manag Sci 14:223-236. doi:10.1007/s10729-011-9151-1

18. Lanner Case studies. (accessed June 2011); Available from: http:/ www.lanner.com/en/case-studies.cfm?offset $=6$

19. Anderson RM, May RM (1991) Infectious diseases of humans: dynamics and control. Oxford University Press

20. Murray CJ, Salomon JA (1998) Modeling the impact of global tuberculosis control strategies. Proc Natl Acad Sci U S A 95 (23):13881-13886

21. Blower SM, McLean AR, Porco TC, Small PM, Hopewell PC, Sanchez MA et al (1995) The intrinsic transmission dynamics of tuberculosis epidemics. Nat Med 1(8):815-821

22. Abu-Raddad LJ, Sabatelli L, Achterberg JT, Sugimoto JD, Longini IM Jr, Dye C et al (2009) Epidemiological benefits of moreeffective tuberculosis vaccines, drugs, and diagnostics. Proc Natl Acad Sci U S A 106(33):13980-13985

23. Dowdy DW, Chaisson RE, Maartens G, Corbett EL, Dorman SE (2008) Impact of enhanced tuberculosis diagnosis in South Africa: a mathematical model of expanded culture and drug susceptibility testing. Proc Natl Acad Sci U S A 105(32):11293-11298

24. Treatment of tuberculosis: guidelines for national programmes, $\mathrm{WHO} / \mathrm{CDS} / \mathrm{TB} / 2003.313$

25. Treatment of tuberculosis guidelines, Fourth Edition, World Health Organisation, WHO/HTM/TB/2009.420

26. FIND (2010), FIND negotiated prices for Xpert ${ }^{\circledR}$ MTB/RIF and Country list, (Accessed June 2011, http://www.finddiagnostics.org/ about/whatwedo/successes/find-negotiated-prices/xpert mtb rif.html

27. Hargreaves NJ, Kadzakumanja O, Whitty CJ, Salaniponi FM, Harries AD, Squire SB (2001) 'Smear-negative' pulmonary tuberculosis in a DOTS programme: poor outcomes in an area of high HIV seroprevalence. Int J Tuberc Lung Dis 5:847-854

28. Swai H, Mugusi F, Mbwambo K (2011) Sputum smear negative pulmonary tuberculosis: sensitivity and specificity of diagnostic algorithm. BMC Res Notes 4:475

29. Rapid Implementation of the Xpert MTB/RIF diagnostic test, Technical and Operational 'How-to' Practical considerations http:// whqlibdoc.who.int/publications/2011/9789241501569_eng.pdf

30. Boehme CC, Nicol M, Nabeta P, Michael JS, Gotuzzo E et al (2011) Feasibility, diagnostic accuracy, and effectiveness of decentralised use of the Xpert MTB/RIF test for diagnosis of tuberculosis and multidrug resistance: a multicentre implementation study. Lancet 377. doi:10.1016/S0140-6736(11)60438-8

31. WHO Guide to Cost Effectiveness Analysis, http://www.who.int/ choice/publications/p_2003_generalised_cea.pdf

32. WHO - Health statistics and health information systems - http:// www.who.int/healthinfo/global burden disease/metrics daly/en/

33. WHO Global Health Observatory Data Repository - Country Statistics - United Republic of Tanzania, 2010 http://apps.who.int/ghodata/ ?vid $=20700 \&$ theme $=$ country

34. Shillcutt SD, Walker DG, Goodman CA, Mills AJ (2009) Costeffectiveness in low and middle income countries. Pharmacoeconomics 27(11):903-917. doi:10.2165/10899580

35. World Bank, World development report - Investing in Health (1993)

36. Lin HH, Langley I, Mwenda R, Doulla B, Egwaga S, Millington KA, Mann GH, Murray M, Squire SB, Cohen T (2011) A modelling framework to support the selection and implementation of new tuberculosis diagnostic tools. Int J Tuberc Lung Dis 15(8):9961004. doi:10.5588/ijtld. 11.0062

37. Moore DA, Shah NS (2011) Alternative methods of diagnosing drug resistance-what can they do for me? J Infect Dis 204(Suppl 4):S1110-S1119 